\title{
Efficiency of the Turkish Stock Exchange with respect to monetary variables: A cointegration analysis
}

\author{
Yaz Gulnur Muradoglu ${ }^{\text {a, }}$, Kivilcim Metin ${ }^{\text {b,** }}$ \\ ${ }^{a}$ Faculty of Business Administration, Bilkent University, 06533 Ankara, Turkey \\ ${ }^{b}$ Department of Economics, Bilkent University, 06533 Ankara, Turkey
}

Received January 1995

\begin{abstract}
In this study, we test the semistrong form of the efficient market hypothesis in Turkey by using the recently developed techniques in time series econometrics, namely unit roots and cointegration. The long run relationship between stock prices and inflation is investigated by assuming the possible existence of a proxy effect. Conclusions are made as to the efficiency of the Turkish Stock Exchange and its possible implications for investors. To our knowledge, this is among the pioneering studies conducted in an emerging market that uses an updated econometric methodology to allow for an analysis of long run steady state properties together with short run dynamics.
\end{abstract}

Keywords: Finance; Economics; Time series; Stock price; Emerging markets

\section{Introduction}

An important set of information which is ignored in the efficient market literature - with only a few exceptions - is the information revealed by macroeconomic variables. Fama concludes his well known review article on efficient markets by encouraging research that "relates the behavior of expected returns to the real economy" (Fama, 1991, p.1610). Macroeconomic variables constitute a relatively more important set of information in thin markets in comparison to mature ones. In thin markets the volume of trade is relatively low, and publicly available information

\footnotetext{
" Corresponding author. e-mail: gulnur@bilkent.edu.tr.

* * e-mail: kivilcim@bilkent.edu.tr.
}

on company performances is generally limited and untimely. Also, most of the thin markets are operational in developing countries where capital accumulation and economic activity is initiated by the state. Therefore, the thinly traded stock markets of controlled economies are expected to absorb fiscal and monetary changes as important sets of information.

Tests of informational efficiency with macroeconomic variables conducted in mature markets are mainly concerned with the estimated correlations between stock prices and output (Fama, 1981; Balvers, Cosimano and McDonald, 1990), money (Pearce and Roley, 1983) and inflation (Fama, 1990; Geske and Roll, 1983; Friedman, 1988; Stulz, 1986). A negative relation between stock returns and inflation was observed and it was suggested that the changes in inflation proxy 
for changes in expected output and price uncertainty: the proxy effect hypothesis. The relationship between stock market returns and inflation was investigated for countries other than the US and UK (Solnik, 1983; Gultekin, 1983) and the Fisherian assumption that predicts a positive relation between expected nominal returns and expected inflation was rejected. Although the relationship between stock returns and inflation was neither stable over time nor stable over the sample countries, regression coefficients were predominantly negative.

The conventional methodology employed in this field of research, briefly reviewed above, is based on the use of time series regressions. The development of cointegration theory in econometrics permits a long-run analysis of the nonstationary time series to study the relationship between stock returns and macroeconomic variables. Using an error correction model of stock prices and testing for the cointegrating relation between stock prices and the variables of interest, Cochran and Defina (1993) investigated the validity of the proxy effect hypothesis for the US. Their empirical work indicates a negative and significant inflation impact. Serletis (1993), using several money supply measures, tested the validity of the monetary portfolio approach as opposed to the efficient markets hypothesis, by employing the Engle and Granger (1987) two step approach and the Johansen (1988) maximum likelihood approach. Serletis (1993) finds that monetary variables and stock prices do not cointegrate in the US market and concludes that the stock market is efficient. Cointegration type of specification incorporates long run constraints on changes in stock prices which are not recognised earlier and includes a variety of possible short run influences.

In this study, we test the semistrong form of the efficient market hypothesis in Turkey by using the recently developed techniques in time series modelling. The relationship between stock prices and inflation is investigated by assuming the possible existence of a proxy effect and, consistent with existing studies, various real, financial and nominal variables are examined. To our knowledge, this is among the pioneering studies conducted in an emerging market that uses an updated econometric methodology to allow for an analysis of long run steady state properties together with short run dynamics.

Accordingly, the paper is organized as follows. After presenting a brief description of the Turkish Stock Exchange and the data set, we analyze the univariate properties of the time series. Dickey and Fuller (1981) unit root tests are used to examine the order of integration and to analyze whether cointegration relationships exist among the variables. The existence of long run equilibrium relations were tested by using the Engle and Granger (1987) two-step approach and the Johansen (1988) maximum likelihood approach that estimate cointegrated systems. The short run dynamics of this relationship are estimated by testing the model using Hsiao's (1981) Final Prediction Error criterion. Evidence is provided for long-run movements of macroeconomic variables and stock prices as well as their short run behavior. Finally, conclusions are made as to the existence of the proxy effect in both the long and the short runs as well as the efficiency of the Turkish Stock Exchange and its possible implications for investors.

\section{The setting}

Turkey, for more than a decade, has functioned as a good case study for the set of developing and post-communist countries in the process of structural change and liberalization. Structural change from a government-regulated economic regime to a market-oriented one commenced with the economic package introduced in January 1980. In 1982, the legal framework for a securities exchange was completed and the stock market was operational by 1986 with the establishment of the Istanbul Securities Exchange (ISE), where 42 companies were listed. In 1993 more than 150 stocks were listed in the ISE and the annual volume of trade was 21 billion US dollars. Still, the financial environment may be described as regulated by restrictive monetary policy and is led by high interest rates and large budget deficits. During the period 1986 to 1993 the annual infla- 
tion rates ranged between $35 \%$ and $70 \%$ and an average growth rate of $5 \%$ was sustained. Under these conditions, Erol and Aydogan (1991) found that portfolio returns display sensitivity to macroeconomic variables such as changes in unexpected inflation and real rate of return by using an arbitrage pricing model. Muradoglu and Onkal (1992) reported a significant lagged relationship between fiscal policy (two months), monetary policy (one and two months) and stock returns indicating the predictive power of government policies on stock returns.

Studies in thin markets are few in number and thus the information sets used to date are quite limited (Boumahdi and Thomas, 1991; Panas, 1990; Barone, 1990; Muradoglu and Unal, 1994). Still, given the distinctive properties of economic regimes in developing countries, tests of informational efficiency should be conducted by accentuating the role of the state, i.e. macroeconomic variables. Trends towards globalization of financial markets require that analysis of efficiency in emerging markets are made on grounds comparable to that of the developed markets, but with appropriate consideration given to the relevant set of information pertaining to these countries.

\section{The data set}

Our data set consists of monthly observations for the period 1986:1-1993:12; all the observations are as of the end of period. Considering the macroeconomics of the Turkish economy, we have set the relations between stock returns and a set of macroeconomic variables that both proxy for inflation and are readily available and not costly (Mishkin, 1982) and are most likely to be used by investors.

Stock returns are represented by the monthly index value of the Istanbul Securities Exchange Composite Index (ISE). Considering the relationship between inflation and the budget deficit (Metin, 1994, 1995) this variable is included in the data set. Budget deficit is represented by the advances of the central bank to the treasury $(A)$ because the budget deficit is not announced on a monthly basis and these advances are widely used in the financial media as indicators of the annual budget deficit. Other variables are also chosen on the basis of the availability and the higher frequency of use of information by the ultimate investor. Interest rates $(R)$ are depicted by the monthly compounded value of the three month treasury bill rate which is a sensitive measure of the 'going rate of interest' in the financial media. The Turkish lira - US dollar exchange rate $(E)$ is also included in the data set due to the frequent open market operations of the Central Bank using dollar reserves. Inflation $(P)$ is measured by the consumer price index. Finally, money supply is represented by two monetary aggregates: M1, which is currency in circulation plus demand deposits, and M2, which is M1 plus time deposits. All data are collected from several issues of the Three Monthly Bulletin of the Turkish Treasury. None of the series are seasonally adjusted.

\section{Methodology}

Two aspects of an econometric approach, which will be implemented in this paper, deserve to be highlighted: non-stationarity and cointegration. First, we consider these in turn. Then, we define a short run dynamic model allowing for an analysis of long run steady state properties with short run dynamics.

\subsection{Non-stationarity}

The starting point of time series analysis is to consider the mechanism which generates the data and its statistical features, particularly its conditional mean and variance. These properties are viewed as being conditional to the past information in the data. The economic series are weakly stationary if the statistical properties of the data are constant over time. In other words, its means and variances are time invariant. If such a series has an autoregressive representation with a white-noise error, it is called integrated of order zero, denoted as $I(0)$. Some series, however, do not satisfy stationarity properties, so they need to be analyzed using different procedures. If the 
autoregressive definition of a model has a unit root as given below,

$x_{t}=\alpha+\beta x_{t-1}+\epsilon_{t}$,

where $\beta=1$, then stationarity is violated. Eq. (1) is a random walk with a drift when $\alpha$ is not equal to zero. A process without a unit root or any other high order roots (explosive roots) is said to be $I(0)$. If the series is integrated $k$ times, it is called $I(k)$, and must be differentiated $k$ times in order to reach $I(0)$. Many economic time series are known to behave like $I(k)$.

In order to test the order of integration the test proposed by Dickey and Fuller (1981) will be used in this article.

$\Delta X_{t}=\beta X_{t-1}+\sum_{j=1}^{p} \delta_{j} \Delta X_{t-j}+c+u_{t}$.

In Eq. (2), $p$ is the number of lags selected to ensure that the residual $u_{t}$ is empirically white noise and $\Delta$ denotes differencing. The test statistic called the augmented Dickey Fuller test (ADF), is based on the $t$-statistic of the parameter $\beta$. The null hypothesis that $H_{0}: X_{t} \sim I(1)$ will be rejected if $\beta$ is negative and significantly different from zero. Tables of critical values have been tabulated by Dickey and are reported in, e.g., Fuller (1976, Table 8.5.2, p.373).

\subsection{Cointegration}

One can examine the series for cointegration between the variables that are related in the economic theory. If we consider a pair of series $X_{t}$ and $Y_{t}$, each of them originally $I(1)$ and having no drift or trend in the mean, then it is expected that their linear combination is $I(1)$. To test for cointegration between a pair of series, one can formulate the cointegration regression as

$Y_{t}=\alpha_{0}+\alpha_{1} X_{t}+u_{t}$,

and test if the residual $u_{t}$ is $I(0)$ or not. The null hypothesis is that $H_{0}: Y_{t}, X_{t}$ are not cointegrated. Tests we have considered in this paper are based on two approaches. The ADF is based on the residuals $u_{t-1}$ from the equation

$\Delta u_{t}=\beta u_{t-1}+\sum_{j=1}^{p} \delta_{j} \Delta u_{t-j}+e_{t}$.
The testing procedures are exactly the same as the one mentioned above: If $\beta$ is less than the critical ADF value, the null hypothesis is rejected.

The second test employed in this study is the maximum likelihood testing procedure suggested by Johansen (1988). This procedure analyses multi-cointegration, directly investigating cointegration in the vector autoregression (VAR) model. If it is known that all series are integrated order one, $I(1)$ or zero, $I(0)$, then the number of noncointegrated components in the series is equal to the number of non-stationary combinations of variables, i.e. the number of unit roots. Denote the vector autoregression of order $p$, where $\left\{X_{t}, t\right.$ $=1, \ldots, T\}$ as given below, by

$\Delta X_{t}=\sum_{i=1}^{p-1} \pi_{i} \Delta X_{t-i}+\pi X_{t-i+1}+C+\epsilon_{t}$,

where $\epsilon_{t}$ are independent $p$ dimensional Gaussian variables with zero mean and variance matrix $\Sigma$ and are stationary. $\pi\left(=\alpha \beta^{\prime}\right)$ is the matrix of long-run responses, where both $\alpha$ and $\beta$ are $N \times r$ for $N$ variables and $r<N$ cointegrating vectors. The rank of $\pi$ determines the dimensionality of the cointegrating space. The $\alpha$ matrix is called the loadings matrix, and provides the weights attached to each cointegrating vector in every equation. $\beta$ can be estimated as the eigenvector associated with the $r$ largest, statistically significant eigenvalues found by calculating

$\left[\mu S_{k k}-S_{k 0} S_{00}^{-1} S_{0 k}\right]=0$,

where $S_{00}$ represents the residual moment matrix from an OLS regression of $\Delta X_{t}$ on $\Delta X_{t-1}, \ldots, \Delta X_{t-k+1} ; \mathrm{S}_{\mathrm{kk}}$ is the residual moment matrix from OLS regression of $X_{t-k}$ on $\Delta X_{t-k+1}$ and $S_{0 k}$ is the cross product moment matrix. Using these eigenvalues, the hypothesis that there are at most $r$ cointegrating vectors can be tested by calculating the loglikelihood ratio test statistic, namely trace test, presented below:

$$
-T \sum_{r+1}^{p} \ln \left(1-\hat{\mu}_{i}\right),
$$

where $\hat{\mu}_{r+1}, \ldots, \hat{\mu}_{p}$ are the $p-r$ smallest eigenvalues. A likelihood ratio test is called the maxi- 
mal eigenvalue test $\left(-T \ln \left(1-\hat{\mu}_{i}\right)\right)$ in which the null hypothesis of $r$ cointegrating vectors is also tested against the alternative of $r+1$ cointegrating vectors. Under the null hypothesis that the eigenvalues are zero, both trace and maximal eigenvalue tests have distributions which are functionals of Brownian motion, the critical values of which are tabulated by Johansen and Juselius (1990) inter alia.

\subsection{Short run dynamic model}

In order to test for the causal effects of inflation and other monetary variables the following short run dynamic model is used:

$\Delta \operatorname{LISE}_{t}=\alpha+\left(\sum_{i=1}^{n} \beta_{i} \Delta X_{t-i}\right)+u_{t}$,

where $\Delta$ denotes first differences, LISE is the natural logaritm of the stock index, and $X_{t-i}$ is the vector of the optimal lagged values on the first differences of the independent variables consisting of inflation ( $\triangle L P)$, exchange rate $(\Delta L E)$, money supply ( $\triangle \mathrm{M} 1)$, interest rate $(\Delta L R)$, and advances of the central bank to treasury ( $\Delta$ LA), $u_{t}$ being the white noise error term.

After conducting the tests for unit roots, first, all variables were transformed to stationary series by the appropriate differencing (first, second, etc.). Then optimal own lag for stock returns and the optimal lags for the independent variables are found by using Hsiao's (1981) final prediction error (FPE) criterion. The FPE statistic is defined as

$\operatorname{FPE}(n)=\frac{T+n+1}{T-n-1} * \frac{\mathrm{RSS}}{T}$,

where $T$ is the number of observations, $n$ ( $n=$ $1,2, \ldots, 12)$ is the length of the lag, and RSS is the sum of squared residuals. We first find the optimal own lag $\left(n^{*}\right)$ of stock returns by choosing the lag $\left(n^{*}\right)$ that minimizes $\operatorname{FPE}(n)$. Then at the second step we run a number of bivariate regressions, each containing the optimal own lag $\left(n^{*}\right)$ and one of the remaining explanatory variables.
For each independent variable added to the equation we calculate

$\operatorname{FPE}\left(n^{*}, k\right)=\frac{T+n^{*}+k+1}{T-n^{*}-k-1} * \frac{\mathrm{RSS}}{T}$,

where $k(k=1,2, \ldots, 12)$ is the lag length on the additional independent variable, and the optimal lag $k^{*}$ is the lag length that minimizes $\operatorname{FPE}\left(n^{*}, k\right)$. If $\operatorname{FPE}\left(n^{*}, k\right)>\operatorname{FPE}\left(n^{*}\right)$, the additional independent variable is dropped from the model assuming that it does not cause stock returns. This step is applied to all independent variables one at a time. The third step involves running trivariate regressions, containing the optimal own lag, the variable with the minimum FPE among bivariate regressions, and a third variable from the remaining independent variables. The same procedure in step two is applied in steps three, four and five, until all remaining variables are either included in or discarded from the model. Using this technique, arbitrary lags and resulting specification errors are avoided (Darrat and Mukherjee, 1987).

\section{Empirical results}

\subsection{Unit roots and testing for the order of integra- tion}

To analyze the univariate time series properties of the data, the Augmented Dickey-Fuller (1981) test was used. The results of the test for the unit roots and the order of integration are presented in Table 1. The first column of Table 1 presents the test statistics for each variable for a unit root in levels. The second column demonstrates the same statistics when the test is repeated for first differences of the variables that have a unit root in the level specification.

No evidence is found against the unit root hypothesis and in all cases the first differenced series do not exhibit a unit root. According to the $\mathrm{ADF}$ test results, all variables of interest are integrated order one, characterized as $I(1)$, with test statistics significant at the $1 \%$ level. 
Table 1

Tests for the order of integration of the variables

\begin{tabular}{llc}
\hline Series & $\begin{array}{l}\text { ADF test } \\
t \text {-statistics (A) }\end{array}$ & $\begin{array}{l}\text { ADF test } \\
t \text {-statistics (B) }\end{array}$ \\
\hline LISE & 1.785 & $-8.351^{* a}$ \\
LP & 3.836 & $-6.000^{*}$ \\
LA & 3.542 & $-8.980^{*}$ \\
LE & 4.781 & $-5.250^{*}$ \\
LR & 0.678 & $-8.095^{*}$ \\
LM1 & 3.021 & $-17.912^{*}$ \\
LM2 & 3.885 & $-10.275^{*}$
\end{tabular}

Notes: 1) (A) denotes that the test statistic that is based on variables in their log levels and (B) denotes that the test statistic is based on variables in first differences of log levels. 2) Each ADF regression initially includes twelve lagged differences to ensure that the residuals are empiricaly white noise. Then a sequential reduction procedure is applied to eliminate the insignificant lagged differences.

3) L denotes the natural logarithm of variables.

4) Critical values for the ADF test statistics are obtained from Fuller (1976, Table 8.5.2).

a * :Significant at $1 \%$.

\subsection{Testing for cointegration}

The null hypothesis of no cointegration between stock prices and variables of interest against at least one available cointegrating vector is tested using both the Engle and Granger (1987) two-step procedure and Johansen's (1988) method of maximum likelihood estimation of multi-cointegrated VAR systems.

The Engle-Granger (1987) two-step procedure involves regressing the concerned variables one by one on stock prices first, to obtain the error terms. Then, the test for the null hypothesis that cointegration exists is based on testing for a unit root in the regression residuals using the ADF tests. The results from the cointegrating regressions are presented in Table 2.

Stock prices appear to be cointegrated with the budget deficit (LA), interest rates (LR), and both money supply measures (LM1, LM2) at the $5 \%$ significance level. Stronger results are obtained when variables are added one by one in cointegrating regressions. It is evident from Table $2 \mathrm{a}$ that the cointegrating regressions including the budget deficit (LA), interest rates (LR) and the price level (LP) can be used to describe the long run trend in stock prices at the 5\% significance level. The result is still significant at the $1 \%$ level when we incorporate the exchange rate (LE) and the narrow definition of money (LM1) into the previous cointegrating regressions.

The static equations (denoted by 'Eq1'-'Eq10') presented in Table $2 b$ are used to analyze the long run steady-state properties of the relationship using OLS to estimate Eq. (3). Considering Eq1 in Table $2 b$, we observe that inflation has a significant negative effect on stock prices, indicating the lack of the proxy effect in the long run. The estimates of the long run static equation also reveal that the trend coefficient and the coefficient for the exchange rates (LE) are significant. In the long run, stock prices are expected to decrease as the Turkish Lira (TL) is devaluated, which can be interpreted as a sign of higher future inflation through higher imported industrial input prices, including oil and other forms of energy. The remaining equations presented in Table $2 b$ demonstrate that the seasonality observed in Eq1 is mainly due to the seasonality in the Central Bank's money supply policy (M1).

Table 2

Test of cointegration between stock prices and macroeconomic variables

(a) ADF tests

\begin{tabular}{ll}
\hline Independent variables & ADF test $t$-statistics \\
\hline LP & $-2.84541^{*}$ \\
LA & $-3.59338^{* a}$ \\
LE & $-2.39152^{*}$ \\
LR & $-3.48798^{*}$ \\
LM1 & $-3.31262^{*}$ \\
LM2 & $-2.92940^{*}$ \\
LA, LR & $-2.16497^{*}$ \\
LA, LR, LP & $-3.95284^{*}$ \\
LA, LR, LP, LE & $-3.69078^{* *}$ \\
LP, LA, LE, LR, LM1 & $-4.23357^{*}$, \\
LP, LA, LE, LR, LM2 & $-3.10000^{*}$
\end{tabular}

Notes: 1) ADF test statistics are based on regressions with twelve lags.

2) The critical values for the ADF test statistics are obtained from Engle and Granger (1987 Table 2).

3) ADF tests are based on the residuals fo the static equations presented in Table $2 \mathrm{~b}$ (also see Eq. (3) in the text).

a " : significant at $5 \%$.

b ** : significant at $1 \%$. 
In the bivariate regressions, each independent variable is significantly related to the stock prices (see Eq6-Eq10). In the multivariate regressions, we observe that money supply and price level have significant coefficients when they enter the equation together (Eq1), but when we enter either money supply (Eq2) or inflation (Eq3) alone, their coefficients do not remain significant. This can be interpreted as the real money balance effect in the long run.

All empirical models are inherently approximations of the actual data generating process and the question is whether the benchmark model (5) is a satisfactorily close approximation. Therefore we investigated the stochastic specification with respect to residual correlation, heteroskedasticity and normality. According to the residual tests reported in Table 3a, the benchmark model (5) seems to provide a reasonably good approximation of the data generating process. There is no indication of residual autocorrelation in any of the series $\left(\left(\mathrm{AR} 1-5 F_{0.99}(5,54) \approx 3.34\right)\right.$. ARCH $5 F$ did not reject homoskedasticity of residuals in any of the series $\left(F_{0.99}(5,49) \approx 3.34\right)$. A few problems remain, such as normality of residuals is accepted for most series except $\triangle \mathrm{LE}$ and $\triangle \mathrm{LR}$ $\left(\chi_{0.99}^{2}(2)=9.21\right)$ and almost all series except $\Delta \mathrm{LA}$ and $\Delta$ LP appear slightly leptocurtic.

Using the procedure suggested by Johansen (1988), cointegration can be investigated by utiliz-

Table 2 (continued)

(b) Static equations (dependent variable = LISE)

\begin{tabular}{|c|c|c|c|c|c|c|c|c|c|c|}
\hline \multirow[t]{2}{*}{$\begin{array}{l}\text { Equation } \\
\text { Number }\end{array}$} & \multicolumn{10}{|c|}{$\begin{array}{l}\text { Independent variables } \\
\text { (absolute value of } t \text {-statistics in parentheses) }\end{array}$} \\
\hline & Constant & Trend & LA & $\mathrm{LE}$ & LR & LM1 & LP & $R^{2}$ & DW & $F$ \\
\hline$\overline{\mathrm{Eq} 1 * \mathrm{c}}$ & $\begin{array}{c}7.46 \\
(1.13)\end{array}$ & $\begin{array}{c}0.80 \\
(2.39)\end{array}$ & $\begin{array}{r}-0.10 \\
(0.86)\end{array}$ & $\begin{array}{c}-2.08 \\
(3.01)\end{array}$ & $\begin{array}{r}-0.27 \\
(0.62)\end{array}$ & $\begin{array}{c}3.13 \\
(4.52)\end{array}$ & $\begin{array}{r}-1.89 \\
(2.30)\end{array}$ & 0.95 & 0.513 & 93.7 \\
\hline $\mathrm{Eq} 2$ & $\begin{array}{l}33.43 \\
(5.51)\end{array}$ & $\begin{array}{c}0.16 \\
(5.12)\end{array}$ & $\begin{array}{c}0.15 \\
(1.16)\end{array}$ & $\begin{array}{r}-2.88 \\
(3.85)\end{array}$ & $\begin{array}{r}-1.55 \\
(2.74)\end{array}$ & $\begin{array}{c}1.00 \\
(0.75)\end{array}$ & - & 0.94 & 0.324 & 75.2 \\
\hline $\mathrm{Eq} 3$ & $\begin{array}{l}28.98 \\
(5.61)\end{array}$ & $\begin{array}{c}0.16 \\
(5.08)\end{array}$ & $\begin{array}{c}0.08 \\
(0.67)\end{array}$ & $\begin{array}{c}-2.78 \\
(3.72)\end{array}$ & $\begin{array}{r}-1.07 \\
(2.37)\end{array}$ & - & $\begin{array}{c}-0.45 \\
(0.53)\end{array}$ & 0.94 & 0.285 & 78.9 \\
\hline $\mathrm{Eq} 4$ & $\begin{array}{l}26.76 \\
(8.39)\end{array}$ & $\begin{array}{c}0.15 \\
(7.90)\end{array}$ & $\begin{array}{c}0.08 \\
(0.66)\end{array}$ & $\begin{array}{r}-2.95 \\
(4.32)\end{array}$ & $\begin{array}{r}-1.06 \\
2.38\end{array}$ & - & - & 0.94 & 0.289 & 84.9 \\
\hline $\mathrm{Eq} 5$ & $\begin{array}{l}26.21 \\
(8.76)\end{array}$ & $\begin{array}{c}0.17 \\
(10.45)\end{array}$ & $\begin{array}{c}0.04 \\
(0.34)\end{array}$ & $\begin{array}{r}-3.79 \\
(6.35)\end{array}$ & - & - & - & 0.94 & 0.263 & 85.6 \\
\hline Eq6 & $\begin{array}{c}8.07 \\
(11.07)\end{array}$ & $\begin{array}{c}0.07 \\
(14.07)\end{array}$ & $\begin{array}{r}-0.50 \\
(4.81)\end{array}$ & $\begin{array}{l}- \\
-\end{array}$ & - & - & - & 0.91 & 0.197 & 60.2 \\
\hline $\mathrm{Eq} 7$ & $\begin{array}{c}27.59 \\
(10.54)\end{array}$ & $\begin{array}{c}0.17 \\
(12.06)\end{array}$ & - & $\begin{array}{r}-3.66 \\
(8.68)\end{array}$ & - & - & - & 0.94 & 0.263 & 93.2 \\
\hline $\mathrm{Eq} 8$ & $\begin{array}{c}14.40 \\
(10.65)\end{array}$ & $\begin{array}{c}0.06 \\
(23.83)\end{array}$ & - & $\begin{array}{l}- \\
-\end{array}$ & $\begin{array}{r}-2.48 \\
(7.08)\end{array}$ & - & - & 0.93 & 0.324 & 77.2 \\
\hline $\mathrm{Eq} 9^{*}$ & $\begin{array}{r}-22.30 \\
(3.44)\end{array}$ & $\begin{array}{c}-0.08 \\
(2.67)\end{array}$ & - & - & - & $\begin{array}{c}3.39 \\
(4.20)\end{array}$ & - & 0.90 & 0.257 & 56.7 \\
\hline Eq10 & $\begin{array}{l}31.81 \\
(5.30)\end{array}$ & $\begin{array}{c}0.21 \\
(5.80)\end{array}$ & - & - & - & - & $\begin{array}{c}-3.85 \\
(4.49)\end{array}$ & 0.90 & 0.163 & 58.2 \\
\hline
\end{tabular}

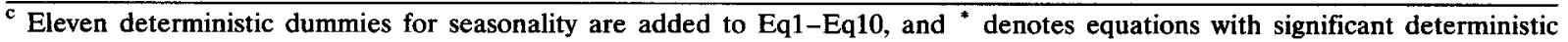
seasonality 
ing the VAR model. Considering the results of the Engle-Granger (1987) two-step procedure, we included only M1 to represent the money supply and the other four variables. During the testing procedure, five order lags are allowed for each variable; a constant, trend, and 11 seasonal dummies are also included into the equation. In the Johansen (1988) trace test, the null hypothesis is that there are at most $r$ cointegrating vectors and it is tested against a general alternative. In the maximum eigenvalue test, the null hypothesis of $r$ cointegrating vectors is tested against $r+1$ cointegrating vectors, as described in the Methodology section of this paper. We present

Table 3

Johansen type multi-cointegration

(a) Residual misspecification test of model (5) ${ }^{\text {a }}$

\begin{tabular}{llrrrrr}
\hline Eq. & $\sigma_{\epsilon}$ & \multicolumn{1}{c}{$\chi^{2}$} & \multicolumn{1}{c}{ skew } & ex.kur & ARCH 5 F & AR1-5 F \\
\hline$\Delta$ LISE & 0.1615 & 8.36 & 0.655 & 1.296 & 0.22 & 0.31 \\
$\Delta$ LA & 0.1196 & 0.42 & -0.178 & 0.208 & 1.22 & 0.17 \\
$\Delta$ LE & 0.0183 & 14.38 & 0.814 & 1.788 & 0.25 & 0.77 \\
LR & 0.0674 & 16.28 & -0.174 & 2.590 & 0.15 & 0.80 \\
$\Delta$ LM1 & 0.0394 & 7.56 & 0.277 & 1.663 & 1.48 & 2.80 \\
$\Delta$ LP & 0.0140 & 1.26 & 0.356 & 0.052 & 0.97 & 1.17
\end{tabular}

${ }^{a} \chi^{2}(2)$ is the Jarque-Bera test for normality ARCH $F_{(\mathrm{df}: 5,49)}$ is the ARCH test for heteroskedastic residuals, and AR $F_{(\mathrm{dr}: 5,54)}$ is the test for residual autocorrelation.

(b) Johansen tests for the cointegrating vectors

\begin{tabular}{lllrr}
\hline Eigenvalues & Null & $\begin{array}{l}\text { Maximum } \\
\text { Alternative }\end{array}$ & Eigenvalue & Trace \\
\hline 0.011968 & $r=0$ & $\mathrm{r} \geqslant 1$ & 1.095663 & 1.095663 \\
0.102732 & $r \leqslant 1$ & $\mathrm{r} \geqslant 2$ & 9.864487 & 10.960150 \\
0.181387 & $r \leqslant 2$ & $\mathrm{r} \geqslant 3$ & 18.213108 & 29.173257 \\
0.201485 & $r \leqslant 3$ & $\mathrm{r} \geqslant 4$ & 20.475104 & 49.648362 \\
0.368780 & $r \leqslant 4$ & $\mathrm{r} \geqslant 5$ & $41.869106^{*} \mathrm{~b}$ & $91.5174680^{*}$ \\
0.512982 & $r \leqslant 5$ & $\mathrm{r} \geqslant 6$ & $65.470322^{*}$ & $156.987790^{*}$ \\
\hline
\end{tabular}

Note: Critical values are taken from Johansen and Juselius (1990, Table A2) for the trace and maximum eigenvalue test statistics. b * :Significant at the $5 \%$ level.

(c) Standardised ( $\left.\beta^{\prime}\right)$ eigenvectors (in rows, largest $\mu$ first)

\begin{tabular}{llrrrrr}
\hline Variable & LISE & \multicolumn{1}{c}{ LA } & \multicolumn{1}{c}{ LE } & \multicolumn{1}{c}{ LR } & \multicolumn{1}{c}{ LM1 } & \multicolumn{1}{c}{ LP } \\
\hline row1 & 1.000 & 0.661 & -3.946 & 8.246 & -1.490 & -2.662 \\
row2 & 0.667 & 1.000 & -13.038 & 1.884 & -1.490 & 17.530 \\
row3 & 0.198 & 0.019 & 1.000 & -0.719 & -1.477 & 0.037 \\
row4 & 0.309 & -0.175 & -0.403 & 1.000 & -5.409 & 5.607 \\
row5 & 0.085 & -0.270 & 1.111 & 0.311 & 1.000 & -0.161 \\
row6 & 0.680 & 0.190 & 5.078 & -1.081 & -0.480 & 1.000 \\
\hline
\end{tabular}

(d) Standardised $\alpha$ coefficients (loadings)

\begin{tabular}{lrrrrrr}
\hline Variable & \multicolumn{1}{c}{ col. 1 } & \multicolumn{1}{c}{ col. 2 } & \multicolumn{1}{c}{ col. 3 } & \multicolumn{1}{c}{ col. 4 } & col. 5 & col. 6 \\
\hline LISE & 0.144 & 0.093 & 0.769 & 0.059 & 0.003 & 0.004 \\
LA & 0.049 & -0.016 & 0.067 & -0.023 & -0.009 & 0.047 \\
LE & -0.021 & -0.001 & 0.023 & 0.007 & 0.018 & 0.002 \\
LR & 0.035 & -0.019 & -0.136 & 0.069 & 0.041 & 0.003 \\
LM1 & 0.006 & 0.016 & -0.070 & -0.031 & 0.076 & 0.003 \\
LP & -0.008 & 0.008 & -0.051 & 0.006 & -0.013 & 0.000 \\
\hline
\end{tabular}


the eigenvalues, maximum eigenvalues, and trace test statistics in Table 3.

According to the critical values of both trace and maximum eigenvalue test statistics, two eigenvalues would be significant at the $5 \%$ level in a Vector Auto-Regressive Model and therefore, there are two cointegrating relationships and four unit roots. This shows that there is a long run relationship between stock prices and inflation proxies.

\subsection{Short run dynamic properties}

Hsiao's (1981) FPE criterion is applied to estimate the short run model presented in Eq. (8). The ADF unit root test results indicated that all variables of interest are once integrated (order one, $I(1))$. Accordingly, all variables of interest are transformed to stationary series by first differencing. Using this procedure, the dependent variable ( $\triangle$ LISE) is measured by the growth rate of stock prices, which could be referred to as stock returns. Utilizing the lagged values of the explanatory variables helps us to test the efficiency hypothesis. If stock returns can be predicted with a lag, this could be used to develop profitable trading rules and the efficiency hypothesis would be rejected.
The empirical results of the short run dynamic model presented in Table 4 indicate that growth rates of interest rates (LR), money supply (LM1) and exchange rates (LE) affect stock returns with a significant lag. The first implication of this finding is that the Turkish Stock Market is not efficient. In other words, publicly available information on monetary policy is not efficiently incorporated into current stock prices, thus enabling the investors to gain abnormal returns by following this policy. Considering the signs of the significant explanatory variables it can be argued that stock returns are expected to increase as growth rates of interest rates fall, and exchange rates increase. Government securities and foreign exchange are known to be substitutes for stocks (Muradoglu, 1991). In the short run, as the Turkish Lira (TL) is devaluated or the interest on government securities is reduced, investors shift their portfolios to include more stocks in the short run.

The second implication is that inflation is not included in the short run model, implying the proxy effect. Instead, money supply (M1) is positively related to stock returns, indicating that monetary expansion in nominal terms results in increased investment in stocks.

Table 4

The short run dynamic model

\begin{tabular}{|c|c|c|}
\hline $\begin{aligned} \overline{\mathrm{LISE}}_{t}= & -0.00109 \\
& (-0.02494)^{\mathrm{a}}\end{aligned}$ & $\begin{array}{l}+0.05303 \Delta \text { LISE }_{t-6} \\
(0.49143)\end{array}$ & $\begin{array}{l}-0.57274 \Delta \mathrm{LR}_{\iota} \\
(-1.97252)\end{array}$ \\
\hline $\begin{array}{l}+0.45894 \Delta \mathrm{LR}_{t-2} \\
(-1.47263)\end{array}$ & $\begin{array}{l}-0.65238 \Delta \mathrm{LR}_{t-3} \\
(-2.11993)\end{array}$ & $\begin{array}{l}-0.76963 \Delta \mathrm{L}_{t-5} \\
(-2.37870)\end{array}$ \\
\hline $\begin{array}{l}-0.48818 \Delta \mathrm{LR}_{t-6} \\
(-1.55668)\end{array}$ & $\begin{array}{l}-0.47392 \Delta \mathrm{LR}_{t-7} \\
(-1.50250)\end{array}$ & $\begin{array}{l}-0.68376 \Delta \mathrm{LR}_{t-9} \\
(-2.18821)\end{array}$ \\
\hline $\begin{array}{l}+0.74715 \Delta \mathrm{LM} 1_{t-1} \\
\quad(2.51132)\end{array}$ & $\begin{array}{l}+0.47176 \Delta \mathrm{LM}_{t-2} \\
\quad(1.71389)\end{array}$ & $\begin{array}{l}+0.34118 \Delta \mathrm{LM} 1_{\mathrm{t}-7} \\
\quad(1.43758)\end{array}$ \\
\hline $\begin{array}{l}-1.83687 \Delta \mathrm{LE}_{t-7} \\
(-2.17706)\end{array}$ & $\begin{array}{l}+2.45310 \Delta \mathrm{LE}_{t-8} \\
\quad(1.51401)\end{array}$ & \\
\hline
\end{tabular}

$R^{2}=0.38, \quad \sigma=0.1750084, \quad F(13,69)=3.29$,

$D-h=2.078, \quad \mathrm{FPE}=0.035794$.

a $t$-values in parentheses. 


\section{Conclusion}

This paper investigates the long run relationship between stock prices and inflation as well as short run dynamics in an emerging market setting, assuming the proxy hypothesis. The first contribution of this paper is that it provides evidence in favor of the proxy hypothesis in the short run, and against it in the long run. In the short run dynamic model, inflation becomes redundant while the growth in the money supply has a positive influence on stock returns, indicating the effectiveness of monetary expansion. The long run steady state results indicate that the negative relation between stock prices and inflation persists when other monetary variables are included in the model. In the long run, the lack of proxy effect can be explained by the positive relation between stock prices and real money balances. Monetary expansion is effective on stock returns in both the short and long term investment horizons in nominal and real terms respectively.

Turkey has experienced structurally high inflation with the average rate being $60 \%$ per annum for the period under consideration. Investors might therefore get accustomed to high rates of inflation, which proxies for other variables and do not respond in the short run. But in the long run, investors might perceive structural inflation as an exogenous shock to the system which creates additional uncertainty that will have an adverse effect on stock investment.

Second, we provide evidence, by means of both the Engle-Granger (1987) and Johansen (1988) procedures, that stock prices and monetary variables cointegrate; there is an error correction representation which is isomorfic to cointegration. The error correction mechanism implies that the change in the dependent variable is related to lagged changes and lagged combination of levels of the variables of interest. This indicates that stock prices can be forecasted and thus, the Turkish Stock Market is not efficient with respect to monetary variables.

The Johansen (1988) procedure suggested that with more than one cointegrating vector, the variables of concern can be used in a short run dynamic structural model. Under these conditions, our next step was the modelling of the Turkish Stock Market for short run equilibrium. Evidence is provided by the short run dynamic properties of the explanatory variables that the Turkish Stock Market assimilates publicly available information on monetary variables with a lag. Since monetary policy moves are not efficiently integrated into current stock returns, we have garnered additional evidence on the inefficiency of the Turkish Stock Market.

Earlier work published on the Turkish Stock Exchange also presents evidence for the lack of the semi-strong form of efficiency of the Turkish Stock Exchange. Inefficiency with respect to monetary policy variables suggests that profit opportunities exist, especially for foreign investors who have a long term investment span and for whom these variables constitute the only easily accessible information set. Unlike foreign investors, domestic investors have a short run investment span in Turkey (Muradoglu, 1991) due to the high inflation rates and related uncertainty. Short run modelling also indicates that a variety of profitable trading rules based on available information on monetary policy can be developed by the diligent investor.

\section{References}

Balvers, R.J., Cosimano, T.F., and McDonald, B. (1990), "Predicting stock returns in efficient markets", The Journal of Finance 45, 1109-1128.

Barone, E. (1990), "The Italian stock market: Efficiency and calendar anomalies", Journal of Banking and Finance 14, 483-510.

Boumahdi, R., and Thomas, A. (1991), "Testing for unit roots panel data: Application to the French stock market efficiency", Economics Letters 37, 77-79.

Cochran, S. J., and Defina, R.H. (1993), “Inflation's negative effects on real stock prices: New evidence and a test of the proxy effect hypothesis", Applied Economics 25, 263-274.

Darrat, A.F., and Mukherjee, T.K. (1987), "The behavior of the stock market in a developing economy", Economics Letters 22, 273-278.

Dickey, D.A., and Fuller, W.A. (1981), "Likelihood ratio statistics for autoregressive time series with a unit root", Econometrica 49, 1057-1072.

Engle, R.F., and Granger, C.W. (1987), "Cointegration and 
error correction: Representation, estimation, and testing", Econometrica 55, 251-276.

Engle, R.F., and Yoo, B.S. (1987), "Forecasting and testing in co-integrated systems", Journal of Eonometrics 35, 143159.

Erol, U., and Aydogan, K. (1991), "Asset pricing in an emerging market: The Turkish case", Paper presented at the 18th Annual Meeting of the European Finance Association, Rotterdam, August, 1991, 29-31.

Fama, E.F. (1981), "Stock returns, real activity, inflation, and money", The American Economic Review 71, 545-565.

Fama, E.F. (1990), "Stock returns, expected returns, and real activity", The Journal of Finance 45, 1089-1108.

Fama, E.F. (1991), "Efficient capital markets: II", The Journal of Finance 46, 1575-1617.

Friedman, M. (1988), "Money and the stock market", Journal of Political Economy 2, 221-245.

Fuller, W.A. (1976), Introduction to Statistical Time Series, Wiley, New York.

Geske, R., and Roll, R. (1983), "The fiscal and monetary linkage between stock returns and inflation", The Journal of Finance 38, 1-33.

Gultekin, N.B. (1983), "Stock market returns and inflation: Evidence from other countries, The Journal Of Finance 38, 49-65.

Hancock, D.G. (1989), "Fiscal policy, monetary policy and the efficiency of the stock market", Economics Letters 31, 65-69.

Hsiao, C. (1981), "Autoregressive modelling and money income causality detection", Journal of Monetary Economics 7, 85-106.

Johansen, S. (1988), "Statistical analysis of cointegration vectors", Journal of Economic Dynamics and Control, 231-254.

Johansen, S., and Juselius, K. (1990), "Maximum likelihood estimation and inference on cointegration - With applications to the demand for money", Oxford Bulletin of Economics and Statistics 52, 169-210.

Metin, K. (1994), "Modelling the public sector deficit of the Turkish economy", Discussion Paper 1, Department of Economics, Bilkent University.

Metin, K. (1995), "An integrated analysis of Turkish inflation", Oxford Bulletin of Economics and Statistics 57/4, 513-531.

Mishkin, F.S. (1982), "Does anticipated monetary policy matter? An econometric investigation", Journal of Political Economy 90, 22-51.

Muradoglu, G. (1991), "Factors influencing the stock demand of individual investors in Turkey", in: Proceedings Izmir Iktisat Kongresi 3, 1-17.

Muradoglu, G., and Onkal, D. (1992), "Turk hisse senedi piyasasinda yari guclu etkinlik" (Semi-strong form efficiency in the Turkish stock market), METU Studies in Development 2, 197-207.

Muradoglu, G., and Unal, M. (1994), "Weak form efficiency in the thinly traded Istanbul Securities Exchange", The Middle East Business and Economic Review 6/2, 37-44.

Panas, E.E. (1990), "The behaviour of Athens stock prices", Applied Economics 22, 1715-1727.

Pearce, D.K., and Roley, V.V. (1983), "The reaction of stock prices to unanticipated changes in money: A Note", The Journal of Finance 38, 1323-1333.

Serletis, A. (1993), "Money and stock prices in the United States", Applied Financial Economics 3, 51-54.

Solnik, B. (1983), "The relation between stock prices and inflationary expectations: The international evidence", The Journal of Finance 38, 35-48.

Stulz, R.M. (1986), "Asset pricing and expected inflation", The Journal of Finance 41, 209-223. 